Review Article

\title{
Interleukin-33 (IL-33) as a Diagnostic and Prognostic Factor in Traumatic Brain Injury
}

\author{
Ali Kemal Erenler $\mathbb{I D}^{1}$ and Ahmet Baydin ${ }^{2}$ \\ ${ }^{1}$ Hitit University, Faculty of Medicine, Department of Emergency Medicine, Çorum, Turkey \\ ${ }^{2}$ Ondokuzmayıs University, Faculty of Medicine, Department of Emergency Medicine, Samsun, Turkey \\ Correspondence should be addressed to Ali Kemal Erenler; akerenler@hotmail.com
}

Received 4 October 2019; Revised 3 December 2019; Accepted 17 December 2019; Published 10 January 2020

Academic Editor: Mario Ganau

Copyright (c) 2020 Ali Kemal Erenler and Ahmet Baydin. This is an open access article distributed under the Creative Commons Attribution License, which permits unrestricted use, distribution, and reproduction in any medium, provided the original work is properly cited.

Interleukin-33 (IL-33) is a cytokine involved in interleukin-1 family. Role of IL-33 in immune system activation is well described in the literature. IL-33 has been identified as an endogenous alarm signal (alarmin) to alert various types of immune cells to trauma. In this narrative review, we aimed to underline the diagnostic and prognostic importance of IL-33 in trauma, particularly in brain trauma.

\section{Introduction}

IL-33 is known to be released from damaged cells following trauma. It is also known as an "alarmin" which means an endogenous signal of tissue injury [1]. It is a nuclear-associated cytokine belonging to IL-1 family and well known with the inducer role in type- 2 allergic immunity [2]. In central nervous system (CNS), IL-33 activates microglias and macrophages in order to limit glial scarring [3, 4]. Here, we sought the utility of IL-33 in traumatic brain injury (TBI).

\section{Materials and Methods}

This narrative review was conducted by entering keywords "interleukin-33" or "IL-33" and "trauma" into MEDLINE/ PubMed, EMBASE, and CINAHL scientific databases. During the database search, we excluded studies which did not relate with the objective by reading the title and abstract. Studies that were not published in English, studies without explanatory abstracts, and studies that do not focus on brain injury were excluded. Two reviewers conducted independent screening and data extraction. First, the reviewers independently screened titles and abstracts of the returned articles to decide if they met the inclusion criteria. Original articles and reviews published in the last 5 years were preferred. If there were studies from the same source, the more recent or more informative study was selected. A total of 23 articles out of 71 studies were included into study.

\section{Structure and Function of IL-33}

Alarmins, including IL-33, are released when a trauma occurs, and their role is to activate immune system against damage [5]. IL-33 is a member of the IL-1 cytokine family along with IL- $1 \alpha$, IL- $1 \beta$, and IL-18 and expressed in structural and lining cells exposed to the environment including fibroblasts, endothelial, and epithelial cells of skin, gastrointestinal tract, and lungs [6,7].

IL-33 shows its effects by activating signaling pathways depending on gene 88 (MyD88) of immune cells which is the primary response gene on the myeloid differentiation expressing the cytokine receptor IL-1 receptor-like 1 (ST2) molecule and signals through a heterodimeric receptor complex comprising an IL-33-specific ST2 coupled with the coreceptor IL-1 receptor accessory protein (IL-1 RAcP), which belongs to other members of the IL-1 cytokine family [8-10]. Following proteolytic cleavage of its precursor pIL33 (full-length IL-33), IL-33 is considered to be released to the extracellular space. When exogenous pathogen-associated molecular patterns (PAMPs) are triggered, IL-33 is 
actively released; however, there is lack of evidence that it is secreted from dendritic cells or mast cells. Unlike other members of the IL-1 family, active IL-33 secretion is independent of caspase- 1 and caspase- 8 (required for cleavage of $\mathrm{pIL}-1 \beta$ and/or pIL-18) or calpain (required for cleavage of pIL- $1 \alpha)$. In vitro, recombinant pIL-33 is cleaved by recombinant caspase-1; however, role of caspase-1 in the cleavage of pIL-33 is not clear [11].

IL-33 serves as an inhibitor of autophagy, and to our knowledge, it is expressed in various organ tissues in the human body, such as endothelial, bronchial, and intestinal epithelial cells $[12,13]$. It is also known that IL-33 is mainly secreted from macroglia, including grey-matter astrocytes and oligodendrocytes [2].

\section{IL-33 and Traumatic Brain Injury}

It is well documented in the literature that TBI is a major cause of morbidity and mortality worldwide. The damage mechanism of TBI is a complex process that may mainly be divided into two categories as primary and secondary brain injury. Primary brain injury is a type of injury directly caused by external force, and the secondary brain injury is a sort of indirect injury containing a complex process in which inflammation plays an essential role [14].

Following an injury or an organ damage and regardless of its type (physical, chemical, or metabolic assault), cells die by necrosis. Following necrosis, rupture and disintegration in a sterile environment occur. This type of traumatic cell death also results in the accumulation of inflammatory cells to the injury site, and a massive immune response triggered by recognition of such danger or alarm signals emerges [15]. Biomarkers such as IL-33 have been considered in the early hours after TBI, and it has been suggested that they could guide clinicians in planning the next stages of patient management [16-19] on a more general perspective, and it should be noted that in some instances, biomarkers already hold the potential for prognostication of mid-and long-term outcomes [20, 21]. The importance of biomarkers is also meant to grow because of innovation in biomedical engineering and point of care detection, with the ultimate goal of coupling them with neuroradiological patterns to define robust biosignatures for TBI patients [22].

Proinflammatory cytokines of the IL- 1 family (IL- $1 \alpha$, IL$1 \beta$, IL-18, IL-33, and IL-36) play essential role on inflammatory and immune processes. These cytokines are released during the early stages of inflammation and, as mentioned before, have been named "alarmins" because they alert the host to induce an inflammatory reaction [12].

In a report, it was stated that the combination of markers including IL-33 improved the prognostic performance and might be used as a useful tool for risk determination in trauma patients [23].

A study with mice showed that IL-33 appeared to downregulate the autophagic activation of apoptosis and the inflammatory response. This downregulation results in protection of mice against injury from collagenase-induced intracerebral hemorrhage. Also, inhibitor role of IL-33 in autophagic activity and apoptosis in neonatal rats was reported. Thus, neurons were not affected from recurrent seizures [12].

In an animal study by Heuvel et al., a weight-drop TBI model was performed to mice, and inflammatory cytokines were measured. In the study, the serum levels of IL-33, IL-1 $\beta$, IL-38, TNF- $\alpha$, IFN- $\alpha$, and IL-19 in the hippocampus were found to be elevated at 3-hour time point [24].

The relationship between trauma and IL-33 was reported in a study with 472 patients. It was found that plasma IL-33 levels elevated on admission and over time in a positive correlation with other cytokines IL-4, IL-5, and IL-13 in patients with blunt trauma [25].

In another study, it was shown that mortality in hospital following blunt trauma was associated with increased plasma sST2 concentrations and suppressed IL-33 levels. Additionally, sST2 levels were found to correlate with injury severity, organ dysfunction, and altered inflammatory response. According to these results, it was concluded that the ST2/IL-33 axis played an important role in the human response to trauma. It was also concluded that sST2 might be a useful biomarker in trauma severity prediction [26].

Elevated serum IL-33 levels after multiple injuries indicate that IL-33 can be referred as an alarmin in human response to polytrauma. It may also be an indicator of the amount of damaged structural cells by mechanical effects of trauma [27]. Damage to central nervous system (CNS) results in IL-33 release, particularly from oligodendrocytes and astrocytes [28].

Foster et al. hypothesized that secretion of IL-33 in response to CNS trauma might initiate a protective feedback loop on neurons involving T cells, glial cells, and monocytes [1]. It was also reported that meningeal ILC2s were activated in an IL-33-dependent manner after CNS injury [29].

In a study using human TBI microdialysate, tissue sections from human TBI, and mouse models of CNS injury, it was revealed that expression of IL-33 in the brain was elevated reaching a maximum after 72 hours in both human samples and mouse models. It was also reported that IL-33 was mainly produced by astrocytes and oligodendrocytes. When brains of mice were deficient in ST2, IL-33 receptor, number of microglia, and macrophages were decreased, and in response damage, their cytokine and chemokine status was altered. These results indicated the essential role of IL-33 in neuroinflammation following TBI. Moreover, IL-33 targets microglia and macrophages in response to damage [30]. Similarly, spinal cord injuries (SCIs) also result in increased IL-33 levels. In the subchronic SCI stage, IL-33 remains elevated particularly in astrocytes' nuclei. Pomeshchik et al. demonstrated that when recombinant IL-33 was given after contusion, SCI results in improved and long-lasting motor recovery, and secondary tissue damage reduces. Even following the initial dose of IL-33, the expression of cytotoxic TNF- $\alpha$ in the injured spinal cord reduced [4]. Literature involved in this review on usefulness of IL-33 in TBI is summarized in Table 1. 
TABLE 1: Comparison of studies on IL-33 in traumatic brain injury involved in the review.

\begin{tabular}{|c|c|c|c|}
\hline Study type & Study design & Conclusion & Reference \\
\hline Original article & A blunt, weight-drop approach to model TBI in mice. & $\begin{array}{l}\text { It was shown that TBI causes the elevation of IL-33, } \\
\text { IL- } 1 \beta, \text { IL- } 38, \text { TNF- } \alpha \text {, IFN- } \alpha \text {, and IL-19 in the } \\
\text { hippocampus at } 3 \text { h time point, and concomitant EI } \\
\text { results in the dose-dependent downregulation of IL- } \\
\text { 33, IL- } 1 \beta, \text { IL- } 38, \text { TNF- } \alpha \text {, IFN- } \alpha \text {, and IL- } 19 .\end{array}$ & {$[24]$} \\
\hline Original article & $\begin{array}{l}\text { Spinal cord of mice was damaged, and recombinant } \\
\text { IL-33 was injected. }\end{array}$ & $\begin{array}{l}\text { Addition of wild-type lung-derived ILC2s into the } \\
\text { meningeal space of IL-33r-/- animals partially } \\
\text { improves recovery after spinal cord injury. IL-33 } \\
\text { released after CNS injury not only initiates a local } \\
\text { response but also a meningeal one through actions of } \\
\text { ILC2s. }\end{array}$ & {$[29]$} \\
\hline Comment & $\begin{array}{l}\text { Comment on "The glia-derived alarmin IL-33 } \\
\text { orchestrates the immune response and promotes } \\
\text { recovery following CNS injury" by Gadani SP, Walsh, } \\
\text { J. T., Smirnov, I., Zheng, J. and Kipnis, J. published in } \\
\text { neuron in } 2015 .\end{array}$ & $\begin{array}{l}\text { Administration of recombinant IL-33 might be } \\
\text { beneficial for treating TBI. }\end{array}$ & {$[1]$} \\
\hline Original article & $\begin{array}{l}\text { Transient focal ischemia was induced by intraluminal } \\
\text { occlusion of the left middle cerebral artery for } 1 \mathrm{~h} \\
\text { with silicone-coated sutures in mice. }\end{array}$ & $\begin{array}{l}\text { IL-33/ST2 signaling was described as a potential } \\
\text { immune regulatory mechanism that enhances the } \\
\text { expression of IL-10 in M } 2 \text { microglia and reduces } \\
\text { acute ischemic brain injury after stroke. }\end{array}$ & {$[28]$} \\
\hline Original article & $\begin{array}{l}\text { Serum ST2 concentrations in } 106 \text { healthy controls } \\
\text { and } 106 \text { severe TBI patients were measured. }\end{array}$ & $\begin{array}{l}\text { Serum ST2 concentrations are significantly related to } \\
\text { inflammation. In TBI, it may be a potential diagnostic } \\
\text { marker. }\end{array}$ & [14] \\
\hline Original article & $\begin{array}{c}\text { Samples from human TBI microdialysate, tissue } \\
\text { sections from human TBI, and mouse models of CNS } \\
\text { injury were used. }\end{array}$ & $\begin{array}{c}\text { IL-33 plays a role in neuroinflammation, and } \\
\text { microglia/macrophages are cellular targets for this IL } \\
\text { following TBI. }\end{array}$ & {$[30]$} \\
\hline
\end{tabular}

\section{Conclusion}

ST2/IL-33 cytokine signaling system has emerged as an intercellular signaling system that participates in processes of the immune response, homeostasis, and tissue injury/ repair. IL-33 is released by endothelial cells, immune cells, and epithelial cells as a result of cell injury or death. There are many extracellular actions of IL-33 including type-2 cytokine production, epithelial repair, and regeneration through amphiregulin, activation of ST2-positive Tregs, and polymorphonuclear neutrophil recruitment and activation [26]. It may be concluded that IL-33 levels tend to increase following TBI. Thus, in combination with other cytokines that take part in tissue damage, it may be used as a diagnostic and prognostic indicator of TBI severity. However, as an inflammatory marker, it must be kept in mind that IL-33 may elevate in various conditions, and diagnosis of TBI must not be based solely on serum IL-33 level.

\section{Conflicts of Interest}

The authors declare that they have no conflicts of interest.

\section{References}

[1] S. L. Foster, S. Talbot, and C. J. Woolf, "CNS injury: IL-33 sounds the alarm," Immunity, vol. 42, no. 3, pp. 403-405, 2015.

[2] A. B. Molofsky, A. K. Savage, and R. M. Locksley, "Interleukin-33 in tissue homeostasis, injury, and inflammation," Immunity, vol. 42, no. 6, pp. 1005-1019, 2015.
[3] Y. Luo, Y. Zhou, W. Xiao et al., "Interleukin-33 ameliorates ischemic brain injury in experimental stroke through promoting Th2 response and suppressing Th17 response," Brain Research, vol. 1597, pp. 86-94, 2015.

[4] Y. Pomeshchik, I. Kidin, P. Korhonen et al., "Interleukin-33 treatment reduces secondary injury and improves functional recovery after contusion spinal cord injury," Brain, Behavior, and Immunity, vol. 44, pp. 68-81, 2015.

[5] Q. Liu, G. K. Dwyer, Y. Zhao et al., "IL-33-mediated IL-13 secretion by ST2+ Tregs controls inflammation after lung injury," JCI Insight, vol. 4, Article ID 123919, , 2019.

[6] J. Schmitz, A. Owyang, E. Oldham et al., "IL-33, an interleukin-1-like cytokine that signals via the IL-1 receptor-related protein ST2 and induces T helper type 2-associated cytokines," Immunity, vol. 23, no. 5, pp. 479-490, 2005.

[7] C. Moussion, N. Ortega, and J. P. Girard, "The IL-1-like cytokine IL-33 is constitutively expressed in the nucleus of endothelial cells and epithelial cells in vivo: a novel "alarmin"?," PLoS One, vol. 3, Article ID e3331, , 2008.

[8] C. Cayrol and J.-P. Girard, "IL-33: an alarmin cytokine with crucial roles in innate immunity, inflammation and allergy," Current Opinion in Immunology, vol. 31, pp. 31-37, 2014.

[9] C. Cayrol and J.-P. Girard, "Interleukin-33 (IL-33): a nuclear cytokine from the IL-1 family," Immunological Reviews, vol. 281, no. 1, pp. 154-168, 2018.

[10] M. Kurowska-Stolarska, A. Hueber, B. Stolarski, and I. B. McInnes, "Interleukin-33: a novel mediator with a role in distinct disease pathologies," Journal of Internal Medicine, vol. 269, no. 1, pp. 29-35, 2011.

[11] S. Hirsiger, H. P. Simmen, C. M. Werner, G. A. Wanner, and D. Rittirsch, "Danger signals activating the immune response after trauma," Mediators of Inflammation, vol. 2012, Article ID 315941, , 2012. 
[12] Y. Ge, M. Huang, and Y.-M. Yao, "Autophagy and proinflammatory cytokines: interactions and clinical implications," Cytokine and Growth Factor Reviews, vol. 43, pp. 38-46, 2018.

[13] C. Moussion, N. Ortega, and J. P. Girard, "The IL-1-like cytokine IL-33 is constitutively expressed in the nucleus of endothelial cells and epithelial cells in vivo: a novel "alarmin"?," PLoS One, vol. 10, Article ID e3331, , 2008.

[14] Q. Du, J.-F. Weng, L.-F. Luo et al., "Serum ST2 as a potential prognostic biomarker for traumatic brain injury," Clinica Chimica Acta, vol. 487, pp. 145-152, 2018.

[15] P. Rider, E. Voronov, C. A. Dinarello, R. N. Apte, and I. Cohen, "Alarmins: feel the stress," The Journal of Immunology, vol. 198, no. 4, pp. 1395-1402, 2017.

[16] S. Hasan, A. Chari, M. Ganau, and C. Uff, "Defining new research questions and protocols in the field of Traumatic Brain Injury through public engagement: preliminary results and review of the literature," Emergency Medicine International, vol. 2019, Article ID 9101235, 8 pages, 2019.

[17] L. Prisco, F. Iscra, M. Ganau, and G. Berlot, "Early predictive factors on mortality in head injured patients: a retrospective analysis of 112 traumatic brain injured patients," Journal of Neurosurgical Sciences, vol. 56, no. 56, pp. 131-136, 2012.

[18] M. Ganau and L. Prisco, "Comment on "neuromonitoring in traumatic brain injury"," Minerva Anestesiologica, vol. 79, no. 3, pp. 310-311, 2013.

[19] M. Ganau, A. Lavinio, and L. Prisco, "Delirium and agitation in traumatic brain injury patients: an update on pathological hypotheses and treatment options," Minerva Anestesiologica, vol. 84 , no. 5, pp. 632-640, 2018.

[20] M. Ganau, N. Syrmos, M. Paris et al., "Current and future applications of biomedical engineering for proteomic profiling: predictive biomarkers in neuro-traumatology," Medicines, vol. 5, no. 1, p. 19, 2018.

[21] V. Di Pietro, M. Ragusa, D. Davies et al., "MicroRNAs as novel biomarkers for the diagnosis and prognosis of mild and severe traumatic brain injury," Journal of Neurotrauma, vol. 34, no. 11, pp. 1948-1956, 2017.

[22] L. Ganau, L. Prisco, G. Ligarotti, R. Ambu, and M. Ganau, "Understanding the pathological basis of neurological diseases through diagnostic platforms based on innovations in biomedical engineering: new concepts and theranostics perspectives," Medicines, vol. 5, no. 1, p. 22, 2018.

[23] D. Rittirsch, V. Schoenborn, S. Lindig et al., "Improvement of prognostic performance in severely injured patients by integrated clinico transcriptomics: a translational approach," Critical Care, vol. 19, no. 1, p. 414, 2015.

[24] F. Olde Heuvel, S. Holl, A. Chandrasekar et al., "STAT6 mediates the effect of ethanol on neuroinflammatory response in TBI," Brain, Behavior, and Immunity, vol. 81, pp. 228-246, 2019.

[25] J. Xu, J. Guardado, R. Hoffman et al., "IL33-mediated ILC2 activation and neutrophil IL5 production in the lung response after severe trauma: a reverse translation study from a human cohort to a mouse trauma model," PLoS Medicine, vol. 14, Article ID e1002365, , 2017.

[26] I. M. Billiar, J. Guardado, O. Abdul-Malak, Y. Vodovotz, T. R. Billiar, and R. A. Namas, "Elevations in circulating sST2 levels are associated with in-hospital mortality and adverse clinical outcomes after blunt trauma," Journal of Surgical Research, vol. 244, pp. 23-33, 2019.

[27] G. Halát, T. Haider, M. Dedeyan, T. Heinz, S. Hajdu, and L. L. Negrin, "IL-33 and its increased serum levels as an alarmin for imminent pulmonary complications in polytraumatized patients," World Journal of Emergency Surgery, vol. 14, p. 36, 2019.

[28] Y. Yang, H. Liu, H. Zhang et al., "ST2/IL-33-Dependent microglial response limits acute ischemic brain injury," The Journal of Neuroscience, vol. 37, no. 18, pp. 4692-4704, 2017.

[29] S. P. Gadani, I. Smirnov, A. T. Smith, C. C. Overall, and J. Kipnis, "Characterization of meningeal type 2 innate lymphocytes and their response to CNS injury," The Journal of Experimental Medicine, vol. 214, no. 2, pp. 285-296, 2017.

[30] G. Wicher, U. Wallenquist, Y. Lei et al., "Interleukin-33 promotes recruitment of microglia/macrophages in response to traumatic brain injury," Journal of Neurotrauma, vol. 34, no. 22, pp. 3173-3182, 2017. 


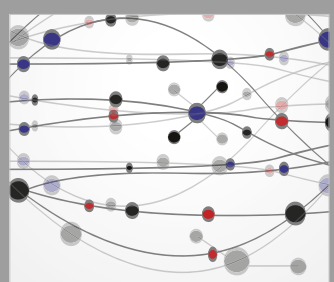

The Scientific World Journal
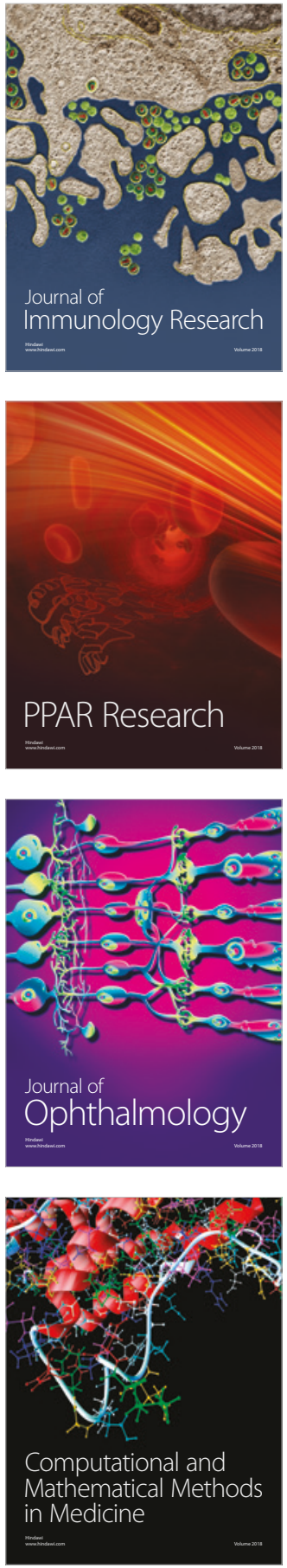

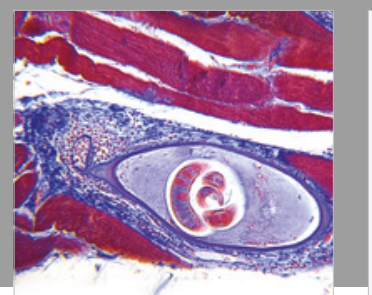

Gastroenterology Research and Practice

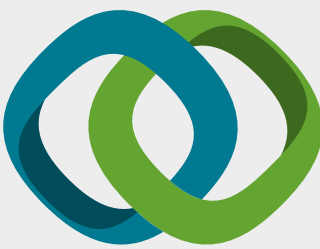

\section{Hindawi}

Submit your manuscripts at

www.hindawi.com
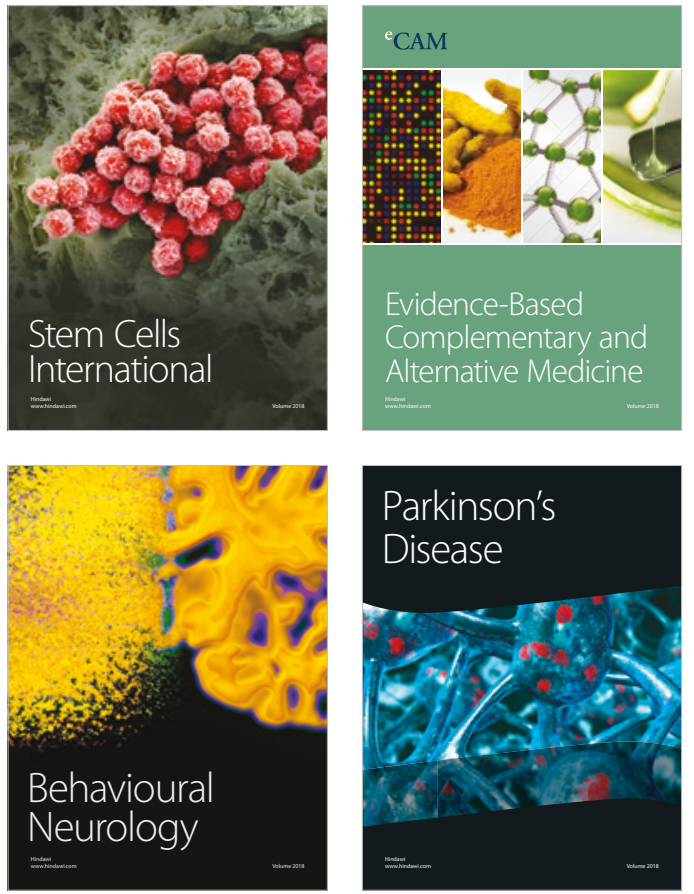

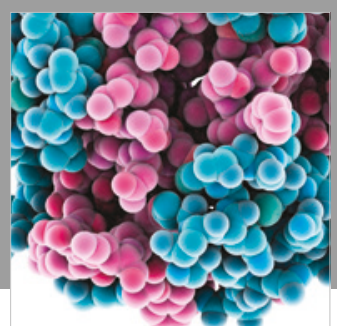

ournal of

Diabetes Research

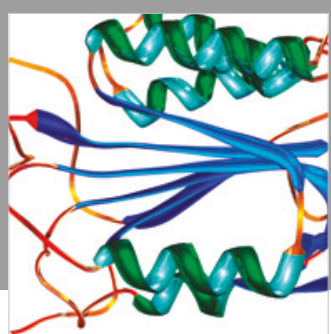

Disease Markers
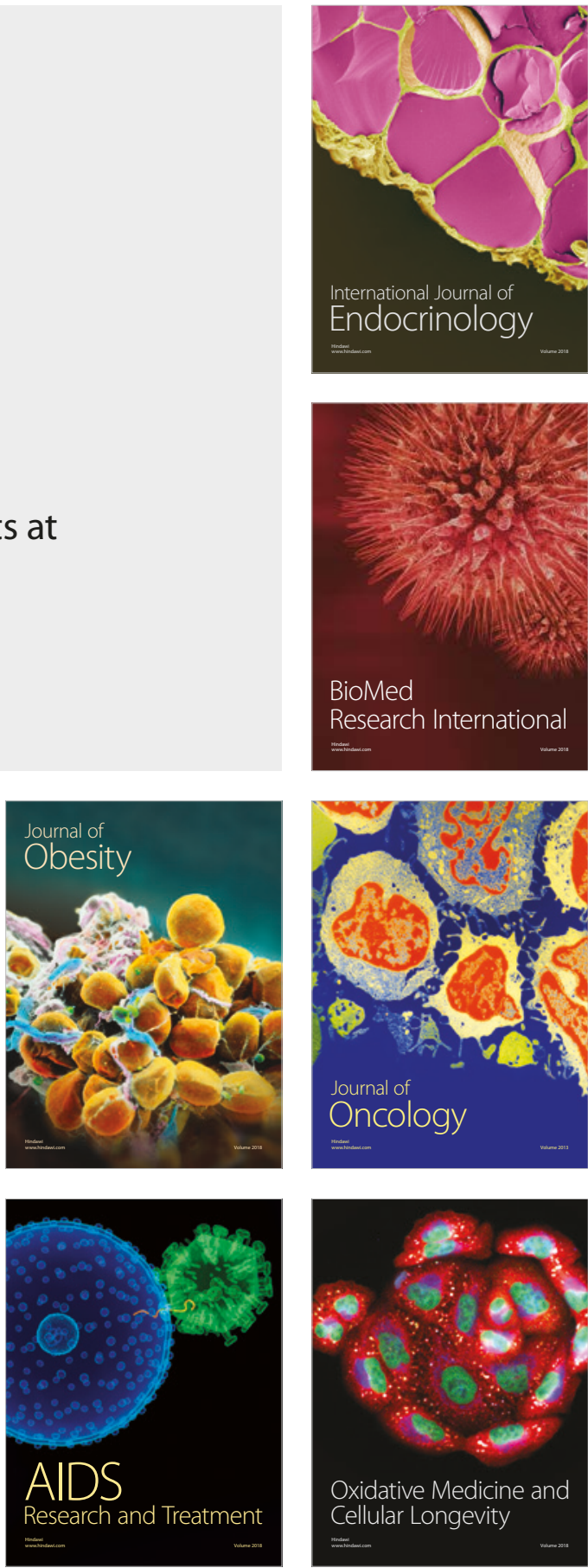